\title{
PILOT STUDY ON PARASITIC FAUNA OF FREE-RANGING INDIAN PEAFOWL (PAVO CRISTATUS)
}

\author{
K.S. Subramanian, Mathew C. John and M. Raman \\ Veterinary University Training and Research Centre, Rajapalayam, Tamil Nadu 626117, India.
}

\begin{abstract}
A survey on endoparasitism among free-ranging peafowl was carried out. Screening of the faecal samples revealed a wide spectrum of nematodes, an unidentified species of cestode egg and two species of coccidian oocysts. The seasonal prevalence of parasites in peafowl are also discussed.
\end{abstract}

\section{Keywords \\ Parasites, peafowl, pilot study}

\section{Introduction}

Hamilton and Zuk (1982) opined that Indian Peafowl (Pavo cristatus) females select the males by assessing the quality of their ornamentation since these characters were good indicators of parasitic load which indirectly revealed the health status of the male. This study has been formulated to understand the prevalence of parasitic fauna among free-ranging peafowls in southern Tamil Nadu.

\section{Materials and Methods}

The study was carried out at two places in southern Tamil Nadu viz., Deer Park, Tirunelveli $\left(77.45^{\circ} \mathrm{E}\right.$ and $\left.8.44^{\circ} \mathrm{N}\right)$ and Vivekananda Kendra, Kanyakumari $\left(77.30^{\circ} \mathrm{E}\right.$ and $\left.8.5^{\circ} \mathrm{N}\right)$ during various seasons from April 1999 to March 2000. Faecal samples collected at weekly intervals were screened by sedimentation technique (Soulsby, 1982) for the presence of parasitic ova. The intensity of endoparasitic infection was assessed as e.p.g (eggs per gram of faeces) using McMaster egg counting chamber as outlined by Roberts and Sullivan (1949). Morphometry of the parasitic ova were measured with an ocular eyepiece scale caliberated by means of a stage micrometer. The droppings containing oocysts of Coccidian were allowed to sporulate in $2 \%$ potassium dichromate solution at room temperature and the time taken for $50 \%$ of the oocysts to complete the sporulation process was recorded as sporulation time (Norton \& Chard, 1973).

\section{Results and Discussion}

The droppings of peafowl were blackish-green in colour, semisolid with mild streaks of urates. The faecal samples revealed a wide spectrum of nematodes, cestode and coccidian oocysts along with other unidentified intestinal protozoan cysts. Among the nematodes observed, higher density was recorded in Heterakis, followed by Ascarid, Capillarid, Syngamus, Strongyloides and Acanthocephalan. In addition to this, Strongyle ova and an unidentified species of Cestode egg were also recorded but in lower densities.

The intensity of helminths were highest during southwest monsoon and lowest during summer, while that of intestinal protozoan was highest during northeast monsoon in both the study areas. Among helminths, ova of Ascarid, Heterakid and Strongyloides were noticed throughout the study period while Capillarid and Syngamus appeared during all seasons except summer. The presence of Heterakid, Syngamus and Capillarid ova throughout the study period could be attributed to the abundance of earthworms which acts as intermediate host for these parasites. The consistent presence of Strongyloides ova throughout the study period might be due to its characteristic heterogenetic lifecycle.

In the present study, the incidence of Strongyle ova was restricted only to southwest monsoon which might be due to the direct life cycle of this parasite that would have limited the availability of third stage infective larvae. Further the incidence of Cestode eggs only during southwest monsoon period might be attributed to the unusual biology of Cestodes in liberating fewer number of eggs inspite of their moderate presence in the intestinal tract as described by Noble and Noble (1964).

Soulsby (1982) reported that the ova of Heterakid from peafowl measured 65-80 x 35-46 $\mu$ which coincided with the observations of the present study. Sloss et al. (1994) opined that it was very difficult to differentiate Ascaridia and Heterakid ova in avian species since both were oval shaped, but could be identified by 
Table 1. Morphology of parasitic ova of peafowl (mean value of 100 ova measured)

\begin{tabular}{|c|c|c|c|}
\hline \multirow[t]{2}{*}{ Parasitic ova } & \multicolumn{2}{|c|}{ Morphometry (in microns) } & \multirow[t]{2}{*}{ Shape and characteristics } \\
\hline & Length & Breadth & \\
\hline Heterakid & 88 & 50 & Oval, smooth shelled with parallel sides \\
\hline Ascarid & 59.5 & 52.5 & Spherical to sub-globular shaped and thick shelled \\
\hline Ascaridia & 90 & 54 & Oval, smooth shelled, barrel shaped sides \\
\hline Syngamus sp. & 49 & 28 & Segmented egg, ellipsoidal with thick operculum at both ends \\
\hline Capillaria sp. & 64 & 34 & Oval, unsegmented egg with bipolar plug \\
\hline Strongyloides sp. & 54 & 28 & Oval, thin shelled egg with larva \\
\hline Acanthocephalan & 68.5 & 42 & Oval, four layered egg with brownish pitted shell \\
\hline Cestode & $62.5^{\star}$ & & Striated thick shelled embryophore with hooklets in onchosphere \\
\hline Oocysts of Coccidia Eimeria sp. & 23.8 & 16.2 & Four sporocysts each containing two sporozoites \\
\hline Isospora sp. & 23.9 & 19.2 & Two sporocysts each containing four sporozoites \\
\hline
\end{tabular}

* Diameter

the barrel like sides of Ascaridia and parallel sides of Heterakid which concurred with the observations of the present study. In addition to this, spherical-shaped, thick-shelled Ascarid ova measuring $59.5 \times 52.5 \mu$ were also noticed in the droppings of peafowl from both the study areas which might be due to the ingestion of small rodents or invertebrates like earthworms, cockroaches etc. that act as paratenic hosts in the life of Ascarid infection.

Soulsby (1982) reported that the Syngamus ova from domestic fowl, turkey and guineafowl measured 70-100 x 43-46 $\mu$ where as the Syngamus ova of peafowl observed in the present study were $50 \times 30 \mu$ in size which might be host specific. The unidentified Cestode eggs isolated from the droppings of both the study areas measuring $62.5 \mu$ in diameter resembled the findings reported by Sloss et al. (1994).

The incidence of Acanthocephalan eggs in the droppings of peafowl might be attributed to the insectivorous feeding habits of peafowl since the larval stages of beetle being the usual invertebrate host, birds would have contracted Acanthocephalan eggs by ingestion of such infected larval beetles.

The mean length and width of Eimeria oocysts in the present study was measured to be $23.8 \times 16.2 \mu$ which resembled the findings of Bhatia and Pande (1996) while the Isospora oocysts measured $23.9 \times 19.3 \mu$ that coincided with the observations of Williams (1978). Patnaik (1965) reported that the oocysts of Isospora species were sporulated in 72 hours whereas in the present study the Eimeria and Isospora species of oocysts were found to sporulate in 60-72 hours and 72-80 hours respectively.

\section{Conclusion}

This study has provided a preliminary database on endoparasitism of peafowl which is an indirect indicator of the health status of the bird. Further region-wise systematic epidemiological studies are needed to record the prevalence of various parasitic fauna among peafowl and to forecast a parasitic map for effective implementation of different control measures.

\section{Acknowledgement}

Authors thank the Tamil Nadu Forest Department for granting permission to carry out this study and the authorities of TANUVAS for the facilities provided.

\section{Reference}

Bhatia, B.B. and B.P. Pande (1966). Development of Eimeria mayurai in a baby peafowl. Indian Journal of Animal Health 7: 105-107.

Hamilton, W.D and M. Zuk (1982). Heritable and true fitness and bright birds; a role for parasites? Science 218: 384-387.

Noble R.E. and G.A. Noble (1964). Parasitology - The Biology of Animal Parasites. ${ }^{\text {nd }}$ ed. Lea and Febiger, Philadelphia. Pp.270-285.

Norton, C.C and M.J. Chard (1973). The oocyst sporulation time of Eimeria species from the fowl. Parasitology 36: 193-198.

Patnaik, M.M (1965). Isospora pellerdyi, new species from Indian Peacock. Indian Journal of Microbiology 5: 67-68.

Roberts, F.H.S and P.J.O. Sullivan (1949). Methods for egg counts and larval cultures for strongyles infecting the gastro-intestinal tract of 
Table 2. Seasonal incidence of endoparasitism among peafowls at Deer Park, Tirunelveli

\begin{tabular}{lllllllllllll}
\hline Season & Mean & Mean & \multicolumn{1}{c}{ M } & \multicolumn{4}{c}{ Helminthic ova } & \multicolumn{3}{c}{ IP } \\
& EPG & OPG & A & H & SY & AC & S & SL & C & CE & CO & I \\
\hline Summer (Apr. to Jun.) & 2600 & 270 & 1180 & 1050 & 0 & 0 & 70 & 300 & 0 & 0 & 200 & 70 \\
Southwest Monsoon (Jul. to Sep.) & 6470 & 1370 & 1200 & 2030 & 670 & 400 & 130 & 470 & 1330 & 230 & 1060 & 300 \\
North East Monsoon (Oct. to Dec.) & 6300 & 1730 & 1200 & 2100 & 1000 & 0 & 0 & 630 & 1370 & 0 & 1470 & 270 \\
Winter (Jan. to Mar.) & 3070 & 270 & 800 & 1270 & 270 & 0 & 0 & 130 & 530 & 0 & 230 & 30 \\
\hline
\end{tabular}

A - ascarid; H - heterakid; SY - syngamus; AC - acanthocephalan; S - strongyle; SL - strongyloides; C - capillarid; CE - cestode; CO - coccidia; I - intestinal protozoan cyst

Table 3. Seasonal incidence of endoparasitism among peafowls at Vivekananda Kendra, Kanyakumari

\begin{tabular}{|c|c|c|c|c|c|c|c|c|c|c|c|c|}
\hline \multirow[t]{2}{*}{ Season } & \multirow{2}{*}{$\begin{array}{l}\text { Mean } \\
\text { EPG }\end{array}$} & \multicolumn{2}{|l|}{ Mean } & \multirow[b]{2}{*}{$\mathrm{H}$} & \multirow[b]{2}{*}{ SY } & \multicolumn{4}{|c|}{ Helminthic ova } & \multirow[b]{2}{*}{ CE } & \multicolumn{2}{|l|}{ IP } \\
\hline & & OPG & A & & & $\mathrm{AC}$ & $\mathbf{S}$ & SL & C & & $\mathrm{CO}$ & $\mathbf{I}$ \\
\hline Summer (Apr to Jun) & 2830 & 300 & 1100 & 630 & 0 & 0 & 0 & 470 & 630 & 0 & 230 & 70 \\
\hline South West Monsoon (Jul to Sep) & 9200 & 1670 & 1500 & 2430 & 1670 & 330 & 130 & 630 & 2170 & 330 & 1300 & 370 \\
\hline North East Monsoon (Oct to Dec) & 8730 & 1970 & 1530 & 2630 & 1800 & 0 & 0 & 1000 & 1770 & 0 & 1530 & 430 \\
\hline Winter (Jan to Mar) & 3200 & 330 & 500 & 1330 & 570 & 0 & 0 & 200 & 600 & 0 & 270 & 70 \\
\hline
\end{tabular}

A - ascarid; H - heterakid; SY - syngamus; AC - acanthocephalan; S - strongyle; SL - strongyloides; C - capillarid; CE - cestode; CO - coccidia; I - intestinal protozoan cyst

cattle. Australian Journal of Agricultural Research 1: 99-103.

Sloss, W.M., R.L. Kemp and A.M. Zajac (1994). Veterinary Clinical Parasitology. $6^{\text {th }}$ ed. Iowa State University Press, Iowa, USA. pp.8085.

Soulsby, E.J.L (1982). Helminths, Arthropods and protozoa of domesticated animals. $7^{\text {th }}$ ed. ELBS, London, 772pp.

Williams, R.B (1978). Notes on some Coccidia of peafowl, pheasants and chickens. Veterinary Parasitology 4: 193-197. 